\title{
Hypertensive heart disease in Africa
}

\section{Akinyemi Aje, Adewole A. Adebiyi and Ayodele O. Falase}

Division of Cardiology, Department of Medicine, University College

Hospital, Ibadan, Nigeria

Address for correspondence:

Dr Akinyemi Aje

Division of Cardiology,

Department of Medicine

University College Hospital

Ibadan

Nigeria

Email:

ajeyemi@yahoo.co.uk

\section{INTRODUCTION}

Hypertension is an important public health problem worldwide. It is also the commonest cardiovascular disease among black Africans. ${ }^{(1)}$ Hypertension is an acknowledged potential risk factor in the development of cardiovascular diseases like stroke, coronary heart disease, renal failure and congestive heart failure..$^{(2,3)}$ The heart is a common target in hypertension.

The response of the heart to the stress/afterload imposed on the left ventricle by the progressively increasing arterial blood pressure is described as hypertensive heart disease. ${ }^{(4)}$ Hypertension is still a very big burden (economically) on the African continent ${ }^{(5-7)}$ despite advances in clinical assessment, investigation, diagnosis, management and prevention.

\section{Epidemiology}

There are different prevalent rates of hypertension in African communities. In general however, the prevalence rate in urban areas is more than in rural areas. Seedat, et al. ${ }^{\left({ }^{8}\right)}$ for example found a prevalence rate of $25 \%$ and $9.4 \%$ among urban and rural Zulus of South Africa respectively. In Nigeria prevalence rates of $9.8 \%$ and $14.6 \%$ were obtained in rural and urban areas. ${ }^{(9)}$

\section{ABSTRACT}

Hypertension has become an important public health problem in Africa. Currently an epidemiologic transition from infectious diseases is going on in the continent and the prevalence of chronic diseases like hypertension is increasing. The response of the heart to the stress/afterload imposed on the left ventricle by the progressively increasing arterial blood pressure is described as hypertensive heart disease. Hypertensive heart disease and failure are the commonest cardiovascular diseases of Africans. Since hypertension is a treatable cardiovascular risk factor, there is need to create more awareness about the disease and educate our patients concerning drug compliance. There is also a need for longitudinal multicentre study in Africa, in order to assess the severity and burden of the disease. SAHeart 2009; 6:42-51

\section{Blood pressure control}

There are few studies in Africa on blood pressure control. However, all the studies tended to show that blood pressure control in Africa is less than optimal. For example, in a study by Isezuo, et al. ${ }^{(10)} 42.7 \%$ blood pressure control rate was achieved among hypertensives managed in a specialised health setting in Nigeria. Data from the United States ${ }^{(I)}$ however revealed that advanced countries have not fared better as only $27 \%$ of hypertensives had good blood pressure control which was still far below the goal of 50\%. In another study in Cape Town, South Africa, Rayner, et al.(12) found that only $39.8 \%$ of hypertensives achieved good blood pressure control rate, a figure which again was still less than optimal.

\section{LEFT VENTRICULAR HYPERTROPHY}

Left ventricular hypertrophy $(\mathrm{LVH})$ is the best studied marker of hypertensive heart disease. (13) Left ventricular hypertrophy is a recognised complication of systemic hypertension. Although for many years LVH was thought to be a beneficial compensatory mechanism for maintaining normal wall stress in left ventricular (LV) pressure and volume overload, ${ }^{(14)}$ epidemio- 
logical studies using electrocardiography (ECG), and more recently echocardiography (Echo), have elucidated the profound independent risk of LVH for congestive heart failure, coronary events, life threatening dysrrhythmias and cardiac mortality. ${ }^{(15,16)}$

Several left ventricular geometric hypertrophy patterns have been found in hypertensives using echocardiographic methods ${ }^{(17-19)}$ and these are classified into four on the basis of left ventricular mass index (LVMI) and relative wall thickness (the ratio of wall thickness to cavity diameter) namely concentric, concentric remodeling, eccentric and normal geometry. These different patterns profoundly influence prognosis. ${ }^{(19)}$ Increasing attention is therefore being paid to left ventricular geometry as it becomes apparent that these specific types may have different pathophysiologic, aetiologic, diagnostic, therapeutic and prognostic significances. ${ }^{(19)}$

Mayet, et al. ${ }^{(18)}$ in the United Kingdom for example found that concentric hypertrophy was present in $40 \%$ of hypertensives, concentric remodelling in 32\%, eccentric hypertrophy in $6 \%$ and normal geometry in 16\%. In Africa, a study of 100 newly diagnosed hypertensives by Aje, et al. ${ }^{(20)}$ showed that $72 \%$ of the patients had abnormal geometric patterns (concentric hypertrophy-28\%, concentric remodelling-26\%, eccentric hypertrophy-18\%). Ogah, et al.(21) in another study in Ibadan, Nigeria found that eccentric hypertrophy was the commonest geometric pattern in hypertensives with ECG LVH with strain.

An assessment of a large number of healthy normotensive subjects yielded an LVM per body surface of $100 \mathrm{~g} / \mathrm{m}^{2}$ and $131 \mathrm{~g} / \mathrm{m}^{2}$ as the cut off for LVH in women and men respectively. LVH was present in 3-7\% of those under 50 years of age and 12-40\% of those between 50 and 80 years of age in the Framingham population using these cut off points. ${ }^{(22)}$ Black patients with mild hypertension have also been found to have twice the prevalence of left ventricular hypertrophy compared with whites who had similar arterial pressures. ${ }^{(23)}$

\section{Physiological hypertrophy}

At this juncture it is important for workers in Africa to distinguish between physiological and pathological hypertrophy. Several workers ${ }^{(24)}$ in Africa have identified the presence of high voltages on the ECG among young Africans and some have even suggested a revision of the criteria for diagnosis of $\mathrm{LVH}$. Others workers in the field have suggested that these are cases of physiological hypertrophy in an active segment of the population. Cardiac hypertrophy occurs during changes in load and is not deleterious in the following conditions: maturation in infancy and childhood, pregnancy and exercise.

The difference in these states is the intermittence or transient duration of excess load compared with the sustained load of hypertension or aortic stenosis. During pregnancy, increased stroke volume and cardiac output is accompanied by a substantial increase in LV dimension and mass, which regresses over months in the postpartum period. ${ }^{(25)}$

The concentric hypertrophy that occurs in a trained athlete who specialises in sports requiring isometric skeletal muscle contraction (i.e. weightlifting, wrestling) or the eccentric hypertrophy that occurs in sports requiring isotonic exercise (i.e. long distance running, cycling) are consistent with normal LV systolic and diastolic function. ${ }^{(26)}$ In the Framingham study, leisure time physical activity was associated with increased LV mass in men but not in women. ${ }^{(27)}$ In an echocardiographic study by Dzudie, et al. ${ }^{(28)}$ on Cameroonian asymptomatic handball players, left ventricular mass indexed, relative wall thickness, left ventricular end diastolic diameter and left atrial diameter were significantly greater in athletes compared to controls.

\section{PATHOLOGIC HYPERTROPHY: CORRELATES OF LEFT VENTRICULAR MASS}

\section{Blood pressure}

LV mass is more closely related to 24 hour blood pressure than casual blood pressure. ${ }^{(29)}$ It is also correlated with office blood pressure possibly as a result of job strain. ${ }^{(30)}$ Palmieri, et al. ${ }^{(31)}$ found that subjects with inappropriately high LV mass had higher ambulatory blood pressures, LV relative wall thickness, and lower LV systolic performance than those with normal LV mass.

\section{Race}

Significant racial differences exist with respect to LV mass. Healthy young blacks have greater LV wall thickness relative to whites. ${ }^{(32)}$ The rate of echocardiographically detected left ventricular hypertrophy in blacks with mild hypertension is twice 
that seen in whites. ${ }^{(23)}$ Gardin, et al. ${ }^{(33)}$ also found that LV mass was higher in blacks.

\section{Sex}

For any given level males appear to have a $15-20 \%$ greater LV mass index than women. ${ }^{(34)}$ This may be due to the $15 \%$ lower lean body mass and maximal oxygen consumption noted in women compared with men. ${ }^{(35)}$

\section{Salt intake}

Salt intake is a major risk factor for hypertension. Studies ${ }^{(36-39)}$ supporting the role of sodium in the genesis of hypertension have shown that there is a positive correlation between urinary sodium excretion and the arterial blood pressure. Salt intake is also a strong determinant of LV wall thickness and LV mass.

Insulin and Insulin Growth Factor-I (IGF-I)

Insulin and glucose metabolism may affect LV geometry.(40) An adverse association has been noted between insulin sensitivity, measured by glucose clamp technique and LV wall thickness in subjects with essential hypertension. ${ }^{(41)}$ Insulin exerts a direct growth promoting effect on cardiomyocytes. IGF-I may also induce cardiac hypertrophy and insulin could stimulate muscle growth by binding to the IGF-I receptors because of the structural similarity between the two molecules. ${ }^{\left({ }^{(42)}\right.} \mid \mathrm{GF}-\mathrm{I}$ is increased and associated with LV mass in subjects with essential hypertension. Insulin and IGF-I are independent determinants of LV mass and geometry. ${ }^{(43)}$

\section{Others}

Obesity, ${ }^{(44)}$ high alcohol intake, ${ }^{(45)}$ plasma viscosity, ${ }^{(46)}$ physical activity, $^{(27)}$ increasing age ${ }^{(47)}$ and genetics ${ }^{(48)}$ have all been shown to influence LV mass.

\section{DEVELOPMENT OF LEFT VENTRICULAR MASS}

Familial predisposition may contribute to increased LV wall thickness as studies have shown the influence of genetics on LV mass, independent of other factors. ${ }^{(49)}$ Increased LV mass precede increases in blood pressure. In the Framingham population increased LV mass was associated with development of hypertension. ${ }^{(50)}$ In another study, higher values of LV mass in normotensive children predicted increase in blood pressure over the following 4 years. $^{(51)}$
Various reasons have been adduced for increased LV mass preceding onset of elevated blood pressure. These include, a hyperdynamic state with increased cardiac output leading to increased LV mass before peripheral arterial resistance and persistent hypertension develops; genetic influences; unobserved but significant periodic blood pressure rises in normotensive subjects and increased psychological stress with associated elevated catecholamine levels which cause increased LV mass before the onset of hypertension.

\section{AETIOPATHOGENESIS}

Increased LV mass (LVH) is mainly due to pressure or volume overload on the heart. Common causes of volume overload state include mitral and aortic regurgitation, chronic anaemia and ventricular septal defects while causes of pressure overload states include systemic hypertension, aortic stenosis, coarctation of aorta and hypertrophic cardiomyopathy.

It is believed that a mechanical signal initiates a cascade of biological events leading to coordinated cardiac growth. The signals for volume pressure overload are either quite different or result in remarkably different patterns and mechanisms of growth. There is an increased myosin heavy chain synthesis by $35 \%$ within hours of pressure overload. This increase is initially predicted by an increase in translational efficiency.(52) In volume overload, the decrease in the myosin heavy chain degradation rate contributes much to the increase in LVM. ${ }^{(53)}$

Both forms of hypertrophy are accompanied by complex changes in gene reprogramming. ${ }^{(54)}$ These changes which include re-expression of immature fetal cardiac genes including the following:

genes that modify motor unit composition and regulation

- genes that encode hormonal pathways e.g. atrial natriuretic factors

genes that modify energy metabolism

Long term changes in gene expression are still unclear. In hypertrophy there is an increase in the number of force generating units (sarcomeres) in the myocytes. Mechanical input is transduced into mechanical event, which modifies gene transcription in the 
nucleus, a possible inducer for this change is local adhesion complex in which integrins connect at the internal cytoskeleton of the cell to the extracellular matrix. ${ }^{(55)}$

Tyrosine-phosphorylated kinases and Serine-threonine kinases (which make up protein kinase C) are implicated in the signalling of hypertrophy. ${ }^{(56)}$ They are found in the extracellular matrix. Though the critical steps in transduction are not understood but there is evidence that disruption of the cell-cell and cell extracellular matrix contact is sufficient to modulate both cell growth and apoptosis, ${ }^{(57)}$ changes in integrin expression and possible shedding into adjacent extracellular matrix accompany chronic hypertrophy. ${ }^{(58)}$ It raises the potential for disordered biochemical signal transduction for growth and suboptimal myocyte extracellular matrix coupling for force generation.

\section{Angiotensin II}

Some have postulated that angiotensin II, via the ATI receptor plays a key role in the induction of hypertrophy because it can directly induce the molecular events of early cardiac growth. ${ }^{(59)}$ The synthetic machinery is unregulated in hypertrophied rat, human myocardium ${ }^{(60)}$ and it is required for the growth of stretched neonatal myocytes in vitro. It is also noteworthy that the observations that pressure overload produces robust hypertrophy in transgenic mice with ATI a receptor knockout ${ }^{(61)}$ show that angiotensin II is mandatory for load induced hypertrophy. Harrap, et al.(62) evaluated correlates of left ventricular mass (LVM) in 84 young healthy subjects aged 16-24 and found a direct role for angiotensin $\|$ in the development of $L V H$. Cardiac renin - angiotensin system has been proposed as an important determinant of hypertrophic response. ${ }^{(63)}$ Regression analysis showed that plasma angiotensin II, renin and angiotensin converting enzyme (ACE) levels correlated significantly with LVM. The importance of angiotensin $\|$ in the development of $\mathrm{LVH}$ in hypertensive patients is also suggested indirectly by the observation that an ACE inhibitor predictably causes regression of $\mathrm{LVH}$ more so than other antihypertensive drugs. ${ }^{(64)}$

\section{Endothelin}

Experimental animal studies suggest that endothelin plays a role in the development of myocardial hypertrophy in response to elevated pressure. ${ }^{(65)}$

\section{Calcineurin}

A calcium calmodulin - dependent phosphatase serves as a master switch for clinical hypertrophy. Transgenic mice that overexpress components of the calcineurin signalling pathway develop a hypertrophic phenotype that can be suppressed by pharmacological inhibitors of calcineurin. ${ }^{(66)}$ Calcineurin inhibitors fail to suppress experimental hypertrophy in several animal models and in humans with hypertension after cardiac transplantation. ${ }^{(67)}$ All these suggest that induced hypertrophy is modulated by redundant signalling pathways with the potential for recruitment of alternate signalling cascades when a single pathway is suppressed. ${ }^{(68)}$

\section{Metalloproteinases (MMPs)}

Matrix metalloproteinases, a family of zinc dependent interstitial enzymes and their tissue inhibitors (TIMPS) control the breakdown of collagen. ${ }^{(69)}$ MMPs are of more relevance in volume overload hypertrophy in which an increase in MMP activation and down regulation of localised tissue inhibitors for the changes in the collagen matrix that prompt chamber expansion. ${ }^{(70)}$ The role of MMPs in concentric hypertrophy is less understood but preliminary observations show that they are activated in experimental pressure overload hypertrophy. Studies ${ }^{(71,72)}$ have also shown that imbalance between MMPs and TIMPs could lead to $\mathrm{LVH}$ and diastolic dysfunction. There are still a lot of controversies concerning ventricular remodelling. ${ }^{(73)}$

\section{Heterometrimeric G Proteins}

Many of the hormones and neurotransmitters implicated in the initiation and exacerbation of myocardial hypertrophy including angiotensin II and endothelin bind to cell membrane receptors which couple to a subset of intracellular heterometrimeric $G$ proteins, the $G$ (q) subclass. Direct evidence for the importance of this subclass is provided by the phenotype of the transgenic mice which selectively over express the carboxyl- terminal peptide of the alpha subunit $G(q) \cdot{ }^{(74)}$

\section{Genetic tendency}

The findings that increased LV mass may precede hypertension and that patients with similar degrees of hypertension may have marked differences in left ventricular mass suggest that genetic factors can promote and retard the development of LVH. This is supported by the increased risk for LVH observed in middle 
aged men with the DD genotype of the ACE gene. ${ }^{(75)}$ The increased risk associated with the DD genotype has been extended to patients who have recently undergone renal transplantation. ${ }^{(76)}$

Most of these studies were conducted outside Africa. Since there may be differences in the pathogenesis of left ventricular hypertrophy in Africa, there is need for similar studies to be conducted in Africa.

\section{PROGRESSION OF LEFT VENTRICULAR} HYPERTROPHY IN AFRICANS

In view of poor or lack of control of hypertension prevalent in Africa, several studies have shown that untreated hypertension was capable of slowly and progressively damaging the heart muscle until it became large and flabby. ${ }^{(77-80)}$ Moreover, other deleterious factors such as excessive alcohol intake also contributed to the destruction process. These will be discussed further later on.

These studies showed that, following the initial thickening of the heart muscle in hypertension, destruction of the heart muscle begins and continues unabated if hypertension remains untreated, albeit slowly and quietly until it reaches a stage when the muscle, together with the important structures embedded within it (i.e. the electrical conducting tissues and coronary arteries), are completely damaged. Eventually, the heart muscle is so destroyed that it is no longer able to support a high blood pressure which therefore falls to normal or subnormal levels. The patient may at this stage present to the doctor as myocardial disease of unknown cause. Some patients are however seen when the blood pressure has not completely normalised and this was in the past wrongly attributed to the effect of heart failure rather than its cause (reactive hypertension).

Why does this happen? Further studies ${ }^{(81)}$ of the effect of hypertension on the heart have shown the following sequence of events. A thickened left ventricle obviously requires supply of additional blood compared with a normal ventricle and the heart does this by appropriating more blood supply for itself. This ensures adequate perfusion and performance of the heart muscle. There is no problem with this process if the thickening is mild and/or the coronary vessels are healthy enough to ensure adequate supply of blood to the thickened myocardial wall. But if the thickening continues unabated, either as a result of poor high blood pressure control or lack of it, and if the coronary vessels are diseased and are not in such a state to ensure adequate perfusion of the muscle wall, the entire muscle wall becomes relatively ischaemic. The effect of this is to provoke formation of scar tissue within the myocardium. This is known as reactive fibrosis. ${ }^{(81,82)}$ The first area of the heart to become relatively ischaemic is the area below the lining of the left ventricle due to the mode of supply of blood to the heart. This is responsible for the common finding of $T$ wave inversion in leads $V 5-V 6$ of the ECG, a phenomenon known as left ventricular strain. ${ }^{(21,83)}$

Some of the individual muscle fibers of the left ventricle may be damaged or completely destroyed in the process not only by the raised blood pressure but also by other injurious factors such as excessive alcohol consumption or myocarditis, and are similarly replaced by scar tissue. ${ }^{(84-87)}$ This type of scar tissue is known as reparative fibrosis.

The end-result of reactive and reparative fibrosis is the same. Scar tissue is not designed to contract and squeeze blood like the original heart muscle fibers. Therefore, replacement of heart muscle fibers with this non-contractile scar tissue leads to initial stiffness of the heart muscle (diastolic dysfunction) and in Africa, it is presumed that the process also leads to weakening of the contractile ability of the entire heart (systolic dysfunction) and consequently, dilatation and failure.

It should be noted that it is not only the myocardial fibers that are damaged by formation of scar tissue. The electrical structure within the heart muscle is also frequently damaged by this process and this causes different grades of heart blocks very often starting with left anterior fascicular block, progressing to right bundle branch block and ultimately complete heart block. Complete left bundle branch block may be seen in those with diffuse left myocardial disease. The destructive process also causes disordered passage of electrical currents across the myocardium creating re-entry mechanisms within it during activation. These result in various forms of arrhythmias.

Left atrial enlargement occurs early in hypertension and is due to the load imposed by hypertension together with systolic and/or 
diastolic dysfunction. A study in our centre ${ }^{(88)}$ showed a 15\% prevalence rate of left atrial enlargement in hypertension. 45\% of hypertensives with echo-derived LVH also had enlarged left atrium. Age, female gender, obesity and LVH were the factors identified to predict left atrial size in our patients.

Generally, an increase in left atrial size correlates closely with chronicity of hypertension and severity of diastolic dysfunction. The results of Framingham studies also showed that left atrial size is an important predictor of atrial fibrillation. However, while atrial fibrillation is often caused by enlarged atrium, left atrial abnormalities (structural and functional) are also well-recognised causes.

Because of these events, those who work in the field of hypertension in Africa must realise that one of the major goals of treatment of patients with hypertension is regression of left ventricular hypertrophy and appropriate drugs such as the angiotensin converting enzyme inhibitors or angiotensin receptor blockers (ACEI/ARBs) are now available for this purpose. ${ }^{\left({ }^{89}\right)}$

\section{HAEMODYNAMICS OF HYPERTENSION IN AFRICA}

These are similar to what obtains in the rest of the world. The left ventricle retains a normal cavity size in mild hypertension. ${ }^{(90)}$ As the level of hypertension becomes moderately or severely increased, significant cavity dilatation develops. ${ }^{(77)}$ Cardiac index is increased in mild hypertensives, normal in moderate ones but decreased in severe cases. Systemic vascular resistance is as expected raised, the rise increasing exponentially with the severity of hypertension. The degree of myocardial hypertrophy also tends to increase progressively with elevated blood pressure becoming more marked in those with moderate and severe hypertension. Left ventricular stroke work and power and pressure time/beat increased with severity of hypertension indicating increased myocardial oxygen consumption. This increase in myocardial oxygen consumption occurs without a corresponding increase in myocardial function. Myocardial contractility indices too decrease in those with moderate and severe hypertension. ${ }^{(90)}$

When heart failure sets in, heart rate increases as expected, ejection fraction drops while all the other myocardial contractility indices deteriorate. ${ }^{(77,90)}$ Despite a drop in stroke volume and cardiac index, systemic vascular resistance remains elevated creating a situation whereby a weak heart is contracting against a high vascular resistance. This has the effect of causing a rapid deterioration of the patient leading to a descent into more severe heart failure and even cardiogenic shock. Recovery of the patient is dependent on normalisation of the systemic vascular resistance.

\section{CLINICAL PRESENTATION}

The incidence of hypertensive heart disease and heart failure is high among hypertensives in Africa. ${ }^{(91)}$ Like in other parts of the world, majority of patients with hypertension are asymptomatic when they first present in the clinic. In our centre, many of the patients who present with diastolic dysfunction may be symptomatic or asymptomatic and clinically, diastolic dysfunction is associated with presence of S4 on cardiac auscultation. Studies from Nigeria have shown that diastolic dysfunction is present in $70 \%$ of Nigerian hypertensives, and about 10\% of these have heart failure with normal systolic function. The majority of the patients with hypertensive heart failure in Africa however have varying degrees of systolic dysfunction and based on the experienced gained at our institution we propose the recognition of four distinct stages of the disease (Falase, unpublished observations).

Stage I - This is the stage of asymptomatic systolic dysfunction. It can only be detected by echocardiography. Cardiac output is maintained by an increase in heart rate but systemic vascular resistance is high. Improvement is dependent on control of $\mathrm{BP}$, preferably with the initial use of ACEI/ARBs and thiazide diuretics.

Stage $\mathbf{2}$ - is characterised by a further decrease in the degree of LV systolic function progressing into the stage of symptomatic systolic dysfunction. Cardiac output may drop or still be maintained by tachycardia but there is a further rise in Systemic Vascular Resistance (SVR). High SVR increases the work of the already compromised heart and this creates a vicious cycle for the heart of the patient. Consequently, LV failure progressively increases and S3 or S4, or S3 and S4 become audible on cardiac auscultation. BP is still recognisably high, usually about $160 / 100 \mathrm{mmHg}$ and above.

Stage 3 - occurs with unrelenting hypertension and at this stage full blown congestive cardiac failure develops. Cardiac output 
drops further still, because although there is tachycardia, this cannot compensate for the drop in stroke volume. SVR on the other hand remains high and there is therefore a rapid decline in cardiac function. On auscultation S3 with or without mitral regurgitation are audible. In later stages, functional tricuspid regurgitation due to $\mathrm{RV} / \mathrm{RA}$ dilatation develops. Measured $\mathrm{BP}$ is above $160 / 90 \mathrm{mmHg}$ but later on systolic BP drops while diastolic BP hovers between $90-95 \mathrm{mmHg}$. This causes an abnormally low pulse pressure. The patient at this stage requires treatment with ACEI/ARBs together with diuretics starting with intravenous frusemide to remove gut oedema and permit adequate drug absorption. This is followed by the use of thiazide diuretics which are effective in controlling the blood pressure of the patients and at the same time removing excess fluid. It should be noted that the blood pressure may sometimes, depending on the myocardial reserve, rise to greater levels following recovery from heart failure. At this stage the patient may require other antihypertensive drugs for control of high blood pressure.

Stage 4 - At this stage BP drops to hypotensive levels. Cardiac output drops further too while SVR remains the same or may rise further. Such patients are in cardiogenic shock which requires powerful inotropic drugs like dopamine or dobutamine infusion for treatment. ACEI/ARBs are contraindicated at this stage because of the low BP. Frusemide is the preferred diuretic.

\section{DIAGNOSIS}

Physical examination is useful in the diagnosis of left ventricular hypertrophy. By palpating the apex beat, it gives a clue to the presence of cardiomegaly or left ventricular hypertrophy with or without dilatation (i.e. displaced or heaving apex beat).

In the past, indirect methods were available for the estimation of the left ventricular size and these included chest $x$-ray (CXR), vectorcardiography and electrocardiography (ECG). Although these indirect methods give useful information and high specificity, they have lower sensitivity and predictive accuracy compared with newer technologies.

A chest $x$-ray is still useful in Africa as it provides a cheap method of diagnosing cardiomegaly and left ventricular enlargement. A cardiothoracic ratio (CTR) greater than $50 \%$ is accepted as an indication of cardiomegaly while left ventricular enlargement is diagnosed when the apex of the heart is displaced to the left and downwards, sometimes below the diaphragm. Very often there is also unfolding of the aorta.

Electrocardiography is similarly cheap and more widely available than echocardiography. Echocardiography is a more expensive procedure although a more accurate form of investigation. Magnetic resonance imaging, thallium imaging and ultra fast CT scanner are other advanced forms of investigations although they are very expensive and are not widely available in Africa.

Some of the eletrocardiographic changes in LVH include increase in QRS voltage, increase in QRS duration and repolarisation abnormalities. Compared with echocardiographic criteria for LVH however, ECG sensitivity is extremely low and it also exhibits limited accuracy. ${ }^{(92)}$

Interethnic differences in ECG characteristics which have been demonstrated especially in blacks are due to the higher praecordial QRS voltages observed in blacks. ${ }^{(93,94)}$

Several studies ${ }^{(95,96)}$ including those conducted in Africa have however found that ECG correlates very poorly with echocardiographic LV mass. Apart from detecting LVH, ECG also provides information related to arrhythmia, conduction defects and myocardial ischaemia. Factors affecting QRS voltage include race, body habitus, age, obesity and chest wall thickness.

Though the awareness and availability of echocardiography in teaching and private hospital is increasing, it is still not widely accessible because of high cost. Echocardiography is the most widely used method for estimating ventricular mass by direct visualisation of the heart. Although M-mode echocardiography is most often used to evaluate LV mass, 2D and 3D echocardiography have also been used. Nonetheless, serial estimates of LV mass are more reproducible by $2 \mathrm{D}$ than with M-mode Echo.

\section{Regression of hypertrophy}

Many studies ${ }^{(64,97)}$ have shown that regression of left ventricular wall thickness and mass occur following administration of antihypertensive therapy and this should be one of the goals of management of hypertensive heart disease in Africa. It should 
be noted that regression of hypertension has also been demonstrated using non pharmacological measures e.g. weight reduction and reduction in salt intake. Reduction of LV mass can be achieved in patients with hypertension and LVH without impairing LV ejection fraction or cardiac output.(98)

Several meta-analyses ${ }^{(64,97)}$ have demonstrated that the common classes of antihypertensive agents decrease LV mass with the exception of direct acting vasodilators (hydrallazine) and some beta blockers with intrinsic sympathomimetic activity. ${ }^{(99)}$

Beneficial effects of reduction in LV mass include:

improved LV filling

increased coronary reserve

decreased cardiovascular mortality and morbidity

- improved mid-wall fractional shortening

increased electrophysiological stability

\section{CONCLUSION}

Hypertensive heart disease is prevalent in Africa and since hypertension is a treatable risk factor, there is need to create more awareness about the disease and educate our patients concerning drug compliance. Each patient should also be assessed for total cardiovascular risk. African countries should provide simple, cost effective hypertension guidelines for their people with the overall aim of preventing the devastating cardiac and other complications of hypertension within the populace. Hypertensive heart disease in Africa continues to be an exciting area and more work needs to be done. There is also a need for longitudinal multicentre study in Africa, in order to assess the severity and burden of the disease. The INTERHEART study ${ }^{(100)}$ has confirmed the rarity of coronary artery disease in black Africans ${ }^{(101,102)}$ and the major risk for coronary artery disease in Africa is hypertension. Comparative studies between Africans and other populations were coronary artery disease is endemic is necessary to identify the major determinants of coronary artery disease.

\section{REFERENCES}

I. Akinkugbe OO. The epidemiology of hypertension in Africa. In : Akinkugbe (Ed.), Cardiovascular disease in Africa. Ciba-Geigy 1976:91-100.

2. Akinkugbe OO. Current Epidemiology of hypertension in Nigeria. Archives of Ibadan Medicine 1999; I ( ):3-5.

3. Mensah GA, Barkey NL, Cooper RS. Spectrum of hypertensive target organ damage in Africa: a review of published studies. J Hum Hypertens 1994;8( I I): 799-808.

4. Frohlich ED, Apstein C, Chobanian AV, et al. The heart in hypertension. N Engl J Med 1992;327(14):998-1008.

5. Seedat YK. Impact of poverty on hypertension and cardiovascular disease in subSaharan Africa. Cardiovasc J Afr 2007; 18(5):316-20.

6. Cooper RS, Rotimi CN, Kaufman JS, et al. Hypertension treatment and control in sub-Saharan Africa: the epidemiological basis for policy. Bmj 1998;316(7/31): 614-7.

7. Norman R, Gaziano T, Laubscher R, et al. Estimating the burden of disease attributable to high blood pressure in South Africa in 2000. S Afr Med J 2007; 97(8 Pt 2):692-8.

8. Seedat YK, Seedat MA, Hackland DB. Prevalence of hypertension in the urban and rural Zulu. J Epidemiol Community Health 1982;36(4):256-61.

9. Non-communicable diseases in Nigeria-Final report of National Survey Federal Ministry of Health-National Expert Committee on NCD. 1997: I2-4I.

10. Isezuo AS, Njoku CH. Blood pressure control among hypertensives managed in a specialised health care setting in Nigeria. Afr J Med Med Sci 2003;32(I):65-70.

II. Burt VL, Cutler JA, Higgins $M$, et al. Trends in the prevalence, awareness, treatment, and control of hypertension in the adult US population. Data from the health examination surveys, 1960 to 1991. Hypertension 1995;26(1):60-9.

12. Rayner B, Blockman M, Baines D, et al. A survey of hypertensive practices at two community health centres in Cape Town. S Afr Med J 2007;97(4):280-4.

13. Frohlich ED. Cardiac hypertrophy in hypertension. N Engl J Med 1987;317: 831-833.

14. Liebson PR, Serry RD. Significance of echocardiographic left ventricular mass. I: Prevalence and correlates of increased left ventricular mass. Cardiol Int 2001;2:53-63

15. Levy D, Garrison RJ, Savage DD, Kannel WB, Castelli WP. Left ventricular mass and incidence of coronary heart disease in an elderly cohort. The Framingham Heart Study. Ann Intern Med 1989; I I0(2): 101-7.

16. Messerli FH, Ventura HO, Elizardi DJ, et al. Hypertension and sudden death Increased ventricular ectopic activity in left ventricular hypertrophy. Am J Med 1984;77(1): 18-22.

17. Ganau A, Devereux RB, Roman MJ, et al. Patterns of left ventricular hypertrophy and geometric remodeling in essential hypertension. J Am Coll Cardiol 1992;19(7): 1550-8.

18. Mayet J, Shahi M, Poulter NR, et al. Left ventricular geometry in presenting untreated hypertension. J Hum Hypertens 1997; I I (9):593-4.

19. Koren MJ, Devereux RB, Casale PN, et al. Relation of left ventricular mass and geometry to morbidity and mortality in uncomplicated essential hypertension. Ann Intern Med 199|; | 4(5):345-52

20. Aje A, Adebiyi AA, Oladapo $\bigcirc$, et al. Left ventricular geometric patterns in newly presenting Nigerian hypertensives: an echocardiographic study. BMC Cardiovasc Disord 2006;6:4

21. Ogah OS, Adebiyi AA, Oladapo OO, et al. Association between electrocardiographic left ventricular hypertrophy with strain pattern and left ventricular structure and function. Cardiology 2006; | 06(1):| 4-2|

22. Burt VL, Whelton P, Roccella EJ, et al. Prevalence of hypertension in the US adult population. Results from the Third National Health and Nutrition Examination Survey, | 988-1991. Hypertension 1995;25(3):305-13. 
23. Hammond IW, Devereux RB, Alderman MH, et al. The prevalence and correlates of echocardiographic left ventricular hypertrophy among employed patients with uncomplicated hypertension. J Am Coll Cardiol 1986;7(3):639-50.

24. Araoye MA. Left vetricular hypertrophy by electrocardiography: A code system applicable to Negroes. Nig Postgrad Med J 1996;3:92-97.

25. Mesa A, Jessurun C, Hernandez A, et al. Left ventricular diastolic function in normal human pregnancy. Circulation 1999;99(4):51 I-7.

26. Colan SD. Mechanics of left ventricular systolic and diastolic function in physiologic hypertrophy of the athlete's heart. Cardiol Clin 1997;15(3):355-72.

27. Savage DD, Levy D, Dannenberg AL, et al. Association of echocardiographic left ventricular mass with body size, blood pressure and physical activity (the Framingham Study). Am J Cardiol 1990;65(5):37I-6.

28. Dzudie A, Menanga A, Hamadou B, et al. Ultrasonographic study of left ventricular function at rest in a group of highly trained black African handball players. Eur J Echocardiogr 2007;8(2): 122-7.

29. Devereux RB, Pickering TG, Harshfield GA, et al. Left ventricular hypertrophy in patients with hypertension: importance of blood pressure response to regularly recurring stress. Circulation 1983;68(3):470-6

30. Schnall PL, Pieper C, Schwartz JE, et al. The relationship between "job strain", workplace diastolic blood pressure, and left ventricular mass index. Results of a case-control study. Jama 1990;263(14): 1929-35.

31. Palmieri V, de Simone G, Roman MJ, et al. Ambulatory blood pressure and metabolic abnormalities in hypertensive subjects with inappropriately high left ventricular mass. Hypertension 1999;34(5): 1032-40

32. Hinderliter AL, Light KC, Willis PWT. Racial differences in left ventricular structure in healthy young adults. Am J Cardiol 1992;69(14): I 196-9.

33. Gardin JM, Wagenknecht LE, Anton-Culver H, et al. Relationship of cardiovascular risk factors to echocardiographic left ventricular mass in healthy young black and white adult men and women. The CARDIA study. Coronary Artery Risk Development in Young Adults. Circulation 1995;92(3):380-7.

34. Devereux RB, Lutas EM, Casale PN, et al. Standardisation of M-mode echocardiographic left ventricular anatomic measurements. J Am Coll Cardiol 1984;4(6): | 222-30.

35. Goble MM, Mosteller M, Moskowitz WB, et al. Sex differences in the determinants of left ventricular mass in childhood. The Medical College of Virginia Twin Study. Circulation 1992;85(5): I 66 |-5.

36. Elliott P, Stamler J, Nichols R, et al. Intersalt revisited: further analyses of 24 hour sodium excretion and blood pressure within and across populations. Intersalt Cooperative Research Group. Bmj 1996;312(7041):1249-53.

37. Staesen J. The assesment of relationship between blood pressure and sodium intake using whole day, day time, and overnight urine collections. J Hypertens 1991;9:1035-1040.

38. Ogunlesi AO, Osotimehin B, Akinkugbe OO. Intracellular sodium and blood pressure in Nigerians. Ethn Dis 1991; I (3):280-7.

39. Olubodun JO, Akingbade OA, Abiola $\bigcirc$. Salt intake and blood pressure in Nigerian hypertensive patients. Int J Cardiol 1997;59(2): I 85- 188

40. Celentano A, Vaccaro O, Tammaro P, et al. Early abnormalities of cardiac function in non-insulin-dependent diabetes mellitus and impaired glucose tolerance. Am J Cardiol 1995;76(16): 1 173-6.

4I. Hill BJ. Insulin as a growth factor. Paediatr Res 1985; 19:879-886.

42. Diez J, Laviades C, Martinez E, et al. Insulin-like growth factor binding proteins in arterial hypertension: relationship to left ventricular hypertrophy. J Hypertens 1995; 13(3):349-55.

43. Verdecchia P, Reboldi G, Schillaci G, et al. Circulating insulin and insulin growth factor-I are independent determinants of left ventricular mass and geometry in essential hypertension. Circulation 1999; 100(17): 1802-7.
44. Lauer MS, Anderson KM, Kannel WB, et al. The impact of obesity on left ventricular mass and geometry. The Framingham Heart Study. Jama 1991;266(2):231-6.

45. Manolio TA, Levy D, Garrison RJ, et al. Relation of alcohol intake to left ventricular mass: The Framingham Study. J Am Coll Cardiol 1991;17(3):717-21.

46. Devereux RB, Drayer Jl, Chien S, et al. Whole blood viscosity as a determinant of cardiac hypertrophy in systemic hypertension. Am J Cardiol 1984;54(6):592-5.

47. Dannenberg AL, Levy D, Garrison RJ. Impact of age on echocardiographic left ventricular mass in a healthy population (the Framingham Study). Am J Cardiol 1989;64(16): 1066-8.

48. Harshfield GA, Grim CE, Hwang C, et al. Genetic and environmental influences on echocardiographically determined left ventricular mass in black twins. Am J Hypertens 1990;3(7):538-43.

49. Post WS, Larson MG, Myers RH, et al. Heritability of left ventricular mass: the Framingham Heart Study. Hypertension 1997;30(5): 1025-8.

50. Post WS, Larson MG, Levy D. Impact of left ventricular structure on the incidence of hypertension. The Framingham Heart Study. Circulation 1994;90( (): 179-85.

5।. Mahoney LT, Schieken RM, Clarke WR, et al. Left ventricular mass and exercise responses predict future blood pressure. The Muscatine Study. Hypertension 1988; 12(2):206-13.

52. Imamura T, McDermott PJ, Kent RL, et al. Acute changes in myosin heavy chain synthesis rate in pressure versus volume overload. Circ Res 1994;75(3):4I8-25.

53. Matsuo T, Carabello BA, Nagatomo Y, et al. Mechanisms of cardiac hypertrophy in canine volume overload. Am J Physiol 1998;275(I Pt 2):H65-74.

54. Swynghedauw B. Molecular mechanisms of myocardial remodeling. Physiol Rev 1999;79(1):215-62.

55. Borg TK, Burgess ML. Holding it all together: organisation and functions of extracellular matrix of the heart failure. Heart Failure 1993:8:230-238.

56. Kuppuswamy D, Kerr C, Narishige T, et al. Association of tyrosine-phosphorylated c-Src with the cytoskeleton of hypertrophying myocardium. J Biol Chem 1997;272(7):4500-8

57. McGill G, Shimamura A, Bates RC, et al. Loss of matrix adhesion triggers rapid transformation-selective apoptosis in fibroblasts. J Cell Biol 1997; | 38(4):90 I - I I.

58. Terracio L, Rubin K, Gullberg D, et al. Expression of collagen binding integrins during cardiac development and hypertrophy. Circ Res 1991;68(3):734-44.

59. Sadoshima J, Izumo S. Molecular characterisation of angiotensin II--induced hypertrophy of cardiac myocytes and hyperplasia of cardiac fibroblasts. Critical role of the ATI receptor subtype. Circ Res 1993;73(3):4I3-23.

60. Studer R, Reinecke H, Muller B, et al Increased angiotensin-I converting enzyme gene expression in the failing human heart. Quantification by competitive RNA polymerase chain reaction. J Clin Invest 1994;94(1):301-10.

61. Harada K, Komuro I, Shiojima I, et al. Pressure overload induces cardiac hypertrophy in angiotensin II type IA receptor knockout mice. Circulation 1998;97(19): 1952-9.

62. Harrap SB, Dominiczak AF, Fraser R, et al. Plasma angiotensin II, predisposition to hypertension, and left ventricular size in healthy young adults. Circulation 1996;93(6): | | 48-54.

63. Dzau VJ. Tissue renin-angiotensin system in myocardial hypertrophy and failure Arch Intern Med 1993;153(8):937-42.

64. Schmieder RE, Martus P, Klingbeil A. Reversal of left ventricular hypertrophy in essential hypertension. A meta-analysis of randomised double-blind studies. Jama 1996;275(19):1507-13.

65. Masaki T, Kimura S, Yanagisawa M, et al. Molecular and cellular mechanism of endothelin regulation. Implications for vascular function. Circulation 199|;84(4): | 457-68. 
66. Molkentin JD, Lu JR, Antos CL, et al. A calcineurin-dependent transcriptional pathway for cardiac hypertrophy. Cell 1998;93(2):215-28.

67. Rowan RA, Billingham ME. Pathologic changes in the long-term transplanted heart: a morphometric study of myocardial hypertrophy, vascularity, and fibrosis. Hum Pathol 1990;21 (7):767-72.

68. Homcy C). Signaling hypertrophy: how many switches, how many wires. Circulation 1998;97(19): 1890-2.

69. Woessner JF, Jr. Matrix metalloproteinases and their inhibitors in connective tissue remodeling. Faseb J 199|;5(8):2145-54.

70. Li YY, Feldman AM, Sun Y, et al. Differential expression of tissue inhibitors of metalloproteinases in the failing human heart. Circulation 1998;98(17): 1728-34.

7I. Saglam M, Karakaya O, Esen AM, et al. Contribution of plasma matrix metalloproteinases to development of left ventricular hypertrophy and diastolic dysfunction in hypertensive subjects. Tohoku J Exp Med 2006;208(2):1 17-22.

72. Ahmed SH, Clark LL, Pennington WR, et al. Matrix metalloproteinases/tissue inhibitors of metalloproteinases: relationship between changes in proteolytic determinants of matrix composition and structural, functional, and clinical manifestations of hypertensive heart disease. Circulation 2006; I I3 (17):2089-96.

73. Opie LH, Commerford PJ, Gersh BJ, et al. Controversies in ventricular remodelling. Lancet 2006;367(9507):356-67.

74. Akhter SA, Luttrell LM, Rockman HA, et al. Targeting the receptor-Gq interface to inhibit in vivo pressure overload myocardial hypertrophy. Science 1998;280(5363):574-7

75. Schunkert H, Hense HW, Holmer SR, et al. Association between a deletion polymorphism of the angiotensin-converting-enzyme gene and left ventricular hypertrophy. N Engl J Med 1994;330(23): 1634-8.

76. Hernandez D, Lacalzada J, Rufino M, et al. Prediction of left ventricular mass changes after renal transplantation by polymorphism of the angiotensinconverting-enzyme gene. Kidney Int 1997;5 I (4): I 205-I I.

77. Lawal SOA, Osotimehin BO, Falase AO. Mild hypertension in patients with suspected dilated cardiomyopathy: cause or consequence. Afr J Med Med Sci 1988; 17(101-112).

78. Falase AO. Four years follow-up of the blood pressure of adult Nigerians with cardiomegaly of unknown origin. Tropical Cardiology 1978;4(14):59-66.

79. Falase AO. Cardiomegaly of Unknown Origin Among Nigerian Adults. Role of Hypertension in its aetiology. Br Heart J 1977;39(6):671-679.

80. Attah EB, Falase AO. Large flabby hearts in hypertension. Am Heart J 1977;94(2): 189-195.

81. Gradman AH, Alfayoumi F. From Left ventricular hypertrophy to congestive heart failure: management of hypertensive heart disease. Progress in Cardiovascular Diseases 2006;48(5):326-34।

82. Diez J, Lopez B, Gonzalez A, et al. Clinical aspects of hypertensive myocardial fibrosis. Curr Opin Cardiol 200 I; 16:328-335.

83. Ogah OS, Oladapo $\bigcirc \bigcirc$, Adebiyi AA, et al. Electrocardiographic left ventricular hypertrophy with strain pattern: prevalence, mechanisms and prognostic implications. Cardiovasc J Afr 2008; 19(1):39-45.

84. Falase AO, Fabiyi A, Ogunba EO. Heart Muscle Disease in Nigerian Adults: A multifactorial disease. Afr J Med Med Sci 1977;6(165-176).

85. Falase $\mathrm{AO}$. Heart muscle disease among adult Nigerians. Role of nutritional factors in its aetiology. European Journal of Cardiology. 1970; 1 0: 197-205.

86. Falase AO. Infections and dilated cardiomyopathy in Nigeria. Heart and Vessel 1985:Suppl 1:232-235.

87. Falase $A O$, Sekoni GA, Adenle AD. Dilated cardiomyopathy in adult Africans: a sequel to infections? Afr J Med Med Sci 1982; 1 I:1-5.

88. Adebiyi AA, Aje A, Ogah OS, et al. Correlates of left atrial size in Nigerian hypertensives. Cardiovasc J S Afr 2005; | 6(3): 158-61.
89. Dahlof B, Penner K, Harrisson L. Reversal of left ventricular hypertrophy in hypertensive patients. A meta-analysis of 109 treatment studies. Am J Hypertens 1992;5: 105-110.

90. Lawal SOA, Falase AO.The effect of hypertension on the heart of adult Nigerians. Tropical Cardiology 1988;14:153-157.

91. Falase AO, Ayeni O, Sekoni GA, et al Heart failure in Nigerian hypertensives. Afr J Med Med Sci 1983;12(1):7-15.

92. Levy D, Labib SB, Anderson KM, et al. Determinants of sensitivity and specificity of electrocardiographic criteria for left ventricular hypertrophy. Circulation 1990;81 (3):815-20.

93. Xie X, Liu K, Stamler J, et al. Ethnic differences in electrocardiographic left ventricular hypertrophy in young and middle-aged employed American men. Am J Cardiol 1994;73(8):564-7.

94. Arnett DK, Rautaharju P, Crow R, et al. Black-white differences in electrocardiographic left ventricular mass and its association with blood pressure (the ARIC study). Atherosclerosis Risk in Communities. Am J Cardiol 1994;74(3): 247-52.

95. Reichek N, Devereux RB. Left ventricular hypertrophy: relationship of anatomic, echocardiographic and electrocardiographic findings. Circulation 1981;63(6): |39|-8.

96. Adenle AD, Katibi IA. Correlation between left ventricular mass and electrocardiographic variables among hypertensive Nigerians. Niger J Med 2001;10(4):182-4.

97. Dahlof B, Pennert K, Hansson L. Reversal of left ventricular hypertrophy in hypertensive patients. A meta-analysis of 109 treatment studies. Am J Hypertens 1992;5(2):95-110.

98. Balogun MO, Dunn FG. Systolic and diastolic function following regression of left ventricular hypertrophy in hypertension. J Hypertens Suppl 1991;9(2):S5 I-5.

99. Liebson PR, Savage DD. Echocardiography in hypertension: a review. II. Echocardiographic studies of the effects of antihypertensive agents on left ventricular mass and function. Echocardiography 1987;4:215-249.

100. Steyn K, Sliwa K, S. H, Commerford PJ, et al. Risk factors associated with myocardial infarction in Africa: The INTERHEART Africa Study. Circulation 2005; | 12:3554-36।.

101. Falase AO, Cole TO, Osuntokun BO. Myocardial infarction in Nigerians. Trop Geogr Med 1973;25:147-150.

102. Falase AO, Oladapo OO, Kanu EO. Relatively low incidence of myocardial infarction in Nigerians. Tropical Cardiology 200 I;27:45-47. 